\title{
An empirical examination of the efficiency of commodity markets in India
}

\section{Ullas Rao*}

Edinburgh Business School, Heriot-Watt University, Dubai Campus, P.O. Box 38103, Dubai Knowledge Park, Blocks 5 and 14, Dubai, UAE

Email: u.rao@hw.ac.uk

*Corresponding author

\section{Vincent Charles}

The University of Buckingham, Hunter Street, Buckingham, MK18-1EG, UK

Email: v.charles@buckingham.ac.uk

\begin{abstract}
In this paper, we examine the efficiency of commodity markets in India by resorting to a rigorous econometric model, namely the cost-of-carry model. By underscoring the need to establish a relationship between the futures and spot markets (given that they depict a time-series behaviour), the proposed model is better positioned to perform the empirical examination of market efficiency when compared to alternative models (such as the variance-ratio test, Jarque-Bera test, and runs test, among others) that have traditionally relied upon the observed behaviour of spot prices alone to achieve the set objective. A review of the existing literature points towards a lack of studies that use statistically robust models, such as cointegration regression, to assess the efficiency of commodity markets in emerging economies. This is particularly true for India, where prices of commodities with their associated impact on inflation always posit a politically sensitive scenario.
\end{abstract}

Keywords: commodity markets; market efficiency; cointegration regression; cost-of-carry; India.

Reference to this paper should be made as follows: Rao, U. and Charles, V. (2021) 'An empirical examination of the efficiency of commodity markets in India', Int. J. Banking, Accounting and Finance, Vol. 12, No. 1, pp.1-15.

Biographical notes: Ullas Rao is serving as an Assistant Professor of Finance in the School of Social Sciences, Heriot-Watt University, Dubai. He obtained his Doctorate in Finance for the work on 'Posterior analysis of mergers \& acquisitions in international financial scenario during the last decade' from the University of Mysore, India, carried out under the guidance of Dr. M.R. Suryanarayana Murthy $(\mathrm{PhD}$, Birmingham, UK). His research makes significant theoretical and empirical contribution by proposing robust approaches for capturing the impact of M\&A activity on the wealth status of shareholders. He has published extensively in journals of international repute. 
Vincent Charles is an experienced researcher in the field of artificial intelligence and management science. He has more than two decades of teaching, research, and consultancy experience in various countries, having been a Full Professor and Director of Research for more than a decade. He holds Executive Certificates from the MIT Sloan School of Management, Harvard Business School, and IE Business School. He has published over 130 research outputs. He is a recipient of many international academic honours and awards, and he is an AWS Certified Cloud Practitioner and an Advance HE Certified External Examiner.

\section{Introduction}

When markets are operating under a weak form, an over-reaction from stock markets is not entirely unexpected (De Bondt and Thaler, 1985). Theoretically, market efficiency defined as the absence of arbitrage opportunities - remains one of the most popular themes applied across asset-classes by researchers seeking empirical validity, with cointegration models being of particular interest (Dwyer and Wallace, 1992). With spot and futures prices exhibiting a non-stationary property, cointegration regression models are best suited to describe the empirical relationship surrounding the cost-of-carry model. Beck (1994) pointed out that commodity markets are not always inefficient but only sometimes inefficient. The examination of commodity market performance in the context of emerging markets (EMs), such as in the case of India, makes for an influential contribution to the existing literature. The study of commodity markets in an influential world economic player such as India merits attention as commodity prices exert a deterministic role in contributing towards inflation and exacerbate the balance-of-payment (BoP) of an economy. Independent regulators (including the monetary authorities) face sustained pressure from elected governments to closely monitor the price movements with an unbinding goal of making market interventions with an overarching objective to build stability amidst prevailing price volatility. As Malkiel (2003) pointed out, even though markets are to be praised for their remarkable ability to utilise information, the mere existence of market efficiency would hinder the ability of professional traders to earn incentives by exploiting the same information.

Although a market intervention may be construed as an euphemism, nonetheless, it is not uncommon to observe elected governments of largely energy import-dependent EM economies resort to market interventions to control surging commodity prices to insulate the domestic sector from adverse economic scenarios. The recent agreement between Russia and the OPEC member Saudi Arabia to restrict oil supply is a case in point (The Wall Street Journal, 2019). Inflationary pressure, along with its concomitant impact on the interest rate, remains a complex politico-economic subject in EMs. It is also not uncommon to observe a price differential in the bullion market in India, as gold prices in India incorporate the domestic demand-supply scenario, with the exchange rate fluctuations further contributing as an additional factor in determining local-currency denominated gold price. In their study, Choudhry and Osoble (2015) made an interesting assertion when pointing towards the weak interdependence between the industry sectors of the USA and EMs. It is in this context that we choose to undertake a study on the efficiency of commodity markets in the Indian context. 
Ever since commodity trading was introduced in the Indian financial markets, the pace of growth has been phenomenal. Multi Commodities Exchange (MCX) of India acts as one of the most important financial markets, facilitating trading in commodity futures markets in India. Data from MCX India (2018) shows that between 2003 and 2018, the volume and value of traded contracts in commodities registered a compounded annual growth rate (CAGR) of $103.33 \%$ and $103.96 \%$, respectively; this reflected the enormous interest posed by both domestic and foreign investors in the commodity markets in India (see Figure A1 in Appendix 1). Given the sensitivity of commodity prices in India, the recently enacted Indian government regulations stipulate severe and several conditions that must be complied with by financial institutions like commercial banks, while embarking on commodity trading (DNA India, 2012). As an example, one of the criteria requires banks to set up an independent subsidiary for trading in commodities. Banks in India have always found commodity trading to be a lucrative source of investment income, and therefore, the existing regulations seek to prevent banks from taking excessive speculative exposure. Interestingly, back in 2010, when India was witnessing extreme inflationary pressure from agricultural commodities, an unsubstantiated claim that gained a lot of traction (including discussions in the Parliament) pertained to the purported manipulation of spot prices of commodities by traders, whose intention was to make profits from their bets on futures contracts. Another layer of peculiarity observed with respect to commodity markets in India pertains to the compulsory physical delivery associated with the futures settlement with regards to some of the commodities (see Appendix 2).

Frontline (2013) carried out a news-article detailing the scandal that broke out at the infamous National Spot Exchange of India (NSEI), which resulted in the loss of INR55 billion to investors. At the heart of the scandal laid the inability on the part of NSEIL to honour the physical delivery of commodities, as it was alleged that trades were executed in the absence of the corresponding inventory with a fraudulent intent to drive prices higher in the first place. An ensuing debate that gained significant attention both in the media and policy circles pertained to the obvious loopholes existing in the commodity markets, leaving these vulnerable to 'market manipulation'. It was natural to further hear questions around the 'efficiency of commodity markets in India'. As previously mentioned, it is in this context that a study on the efficiency of commodity markets in India makes an important contribution to the extant literature.

\section{Cost-of-carry model}

There are significant studies that have been carried out to examine market efficiency using the cost-of-carry model. It is interesting to observe that almost all the studies have been devoted to examining a singular form of market efficiency: weak, semi-strong or strong. Unfortunately, none of these studies have a compelling practical implication. Even as we examine the market efficiency of commodity markets in India, we employ the cost-of-carry model to investigate the claim surrounding the impact of futures prices on spot prices, paving the way for an important policy contribution. Chan et al. (1991) observed the intraday relationship between returns and return volatility, which indicated a 
strong intermarket dependence in the volatility of the cash and futures returns. Wahab and Lashgari (1993) employed the cost-of-carry model to carry out a cointegration analysis examining the linkage between the stock index and stock index price futures for both the S\&P 500 and FTSE 100 indexes over the period from 1988 to 1992. Following the evidence of strong interdependence between stock index cash and futures market, the results supported market efficiency, making it one of the very few studies to lead to such an inference. Brenner and Kroner (1995) employed the cost-of-carry model to show the existence of cointegration between spot and futures prices, asserting that the same is dependent on the time-series properties of the cost-of-carry.

Highlighting the informational role of the futures market, Rittler (2012) addressed the question of information transmission in European spot and futures market, with the results indicating that the price discovery process in the European allowance markets is similar to the one in more mature markets. Zavadska et al. (2018) argued that it is not always conceivable to determine the exact nature of causality between oil spot and futures prices, leading to significant disagreements and incongruities among researchers. Inani (2018) observed that out of ten most liquid commodities traded in the agricultural futures contracts in India, six followed price discovery in the futures market. This led to the conclusion that the futures market for agricultural commodities was superior and more sophisticated in comparison to the spot market. A practical implication of this result is that financial markets for futures appear to be informationally more efficient than the spot markets, which often mirror the opaque demand-supply function observed in the physical market. Looking at the precious metals, Charles et al. (2015) observed downward trends in respect of return predictability of gold and silver markets, implying an improvement of the weak-form efficiency of these markets. Further, gold was observed to be the most efficient market among precious metals. In light of the wide discrepancy existing between physical and synthetic gold (gold ETFs, derivative contracts, etc.), the inference drawn at least in respect of gold must be interpreted with extreme caution.

As it can be seen in Hansen and Hodrick (1980), Kellard et al. (1999), and McKenzie and Holt (2002), one of the plausible models of market efficiency pertains to using futures prices as a predictor of future spot prices. However, as EM economies like India are characterised by the unavailability of reliable data on future spot prices, the cost-ofcarry model presents the best alternative. More significantly, in studies using futures prices as an unbiased predictor of future spot prices, results on market efficiency remain inconclusive with some finding evidence of efficiency while others finding inefficiency (Heaney, 2002). Following Joyeux and Milunovich (2010) and Crowder and Phengpis (2005), who also employed the cost-of-carry model to examine the market efficiency surrounding the EU carbon futures market, we apply a similar model to test the efficiency of the Indian commodity market. The cost-of-carry model is most popularly employed to estimate the forward/futures price of assets. Based on the principle of continuous compounding, the model is used to price forward/futures contracts given the time duration and based on the settlement of the contract, compounded continuously for a given rate of interest (Hemler and Longstaff, 1991). Mathematically, under the cost-of-carry model ${ }^{1}$, the futures price is expressed as a function of the underlying spot price, as follows:

$$
F_{t, T}=S_{t} e^{r_{t}(T-t)}
$$


where

$F_{t, T} \quad$ futures price over the period from $t$ to $T$

$S_{t, T} \quad$ spot price over the period from $t$ to $T$

$r_{t, T} \quad$ rate of interest over the period from $t$ to $T$

$t \quad$ time at the start of the contract

$T$ time to maturity.

Let us explain the above mathematical notation. Say that the spot price of the commodity is $S_{t}$ with the futures expiring in $t$-months and a $T$-bill rate of $\mathrm{r} \%$; by applying the cost-of-carry model, the computed futures price is $F_{t}$. Now, if the spot price converges exactly towards the futures price at the end of the $t$-months, then the hedge is considered to be perfect. However, if there is a price differential between the spot and futures price, there will be an opportunity for the trader to exploit such price differential to earn profits by engaging in arbitrage opportunities. The cost-of-carry model, therefore, plays an influential role in determining the futures prices.

Given the time-series nature of the variables represented in equation (1) above, we would expect the variables to have unit roots, i.e., non-stationary or $I(1)$. In such a scenario, the application of conventional regression would be rendered spurious, deeming the results unreliable (Gujarati and Porter, 2009).

We employ the cointegration regression model and express the above relationship as a cointegration regression equation by transforming the variables into a logarithmic function. Taking the natural logarithms, the above equation may be expressed as follows:

$$
f_{t}=s_{t}+r_{t}(T-t)+\mu_{t}
$$

where

$$
\begin{gathered}
f_{t} \equiv \log F_{t} \\
s_{t} \equiv \log S_{t}
\end{gathered}
$$

and $\mu_{t}$ is a white noise term with mean ' 0 ' and variance $\sigma^{2}$ determined by market imperfections.

Empirically, the above equation may be re-specified as follows:

$$
f_{t}=\alpha s_{t}+\beta r(T-t)+\mu_{t}
$$

Provided that $\mu_{t}$ is stationary, we perform the following single and joint hypotheses testing:

$1 \quad \mathrm{H}_{0}: \alpha=1$

$2 \mathrm{H}_{0}: \beta=1$

$3 \mathrm{H}_{0}: \alpha=\beta=1$. 
The above are the restrictions applied by the cost-of-carry model. In essence, the application of the above constraints forming the bases of the above hypotheses, implies that as long as the cost-of-carry principle holds good, spot prices will converge with futures prices on a future date. If that is not the case (which is a practical reality), opportunities exist for the arbitrageurs to exploit the differentials between the futures and spot prices and thereby make a profitable trade. Such an outcome runs contrary to the principles of market efficiency.

\section{Findings of the study}

As delineated above, we look at the efficiency of commodity markets in India by selecting commodities from each of the following markets: agriculture, oil and precious metals. We select cotton, crude oil, and gold as the most representative individual commodities reflecting each of the above markets, respectively. The daily spot and futures prices denominated in INR were collected over a period of 180 days (equivalent to a six-month contract) ending in August 2018.

The descriptive statistics entailing the spot and futures prices of each of the commodities are presented in Table 1.

From Table 1, it is evident that the standard deviation of crude oil of both spot and futures prices is the highest. This is not uncommon given the sensitivity of crude oil prices to a range of geopolitical-economic factors. Both crude oil and gold are observed to be negatively skewed, indicating a higher probability of left-tail risks as opposed to cotton. With the kurtosis values observed to be less than 3, each of the commodities appears to bear a platykurtic distribution. Lastly, at 1\% level of significance, the JB test prob. values reject the null hypothesis underlying normality, paving the way for a price disequilibrium.

Having hypothesised that the variables represented in equation (2) are $I(1)$, we perform the unit root tests for which the results are indicated in Table 2.

From Table 2, it is clear that we are unable to reject the null hypothesis involving the presence of unit roots, implying that the variables represented by futures, spot, and interest rate have unit roots and are, therefore, non-stationery, i.e., $I(1)$.

We know that:

$$
Y_{t}=Y_{t-1}+\mu_{t}
$$

is non-stationary, and therefore, $I(1)$. However, when the same equation is expressed as:

$$
\mu_{t}=Y_{t}-Y_{t-1}=\Delta Y_{t}
$$

then the series becomes stationary, and therefore, $I(0)$. Hence, we convert the variables into first differences and test for the presence of unit roots. The results are depicted in Table 3 . 
Table 1 Descriptive statistics

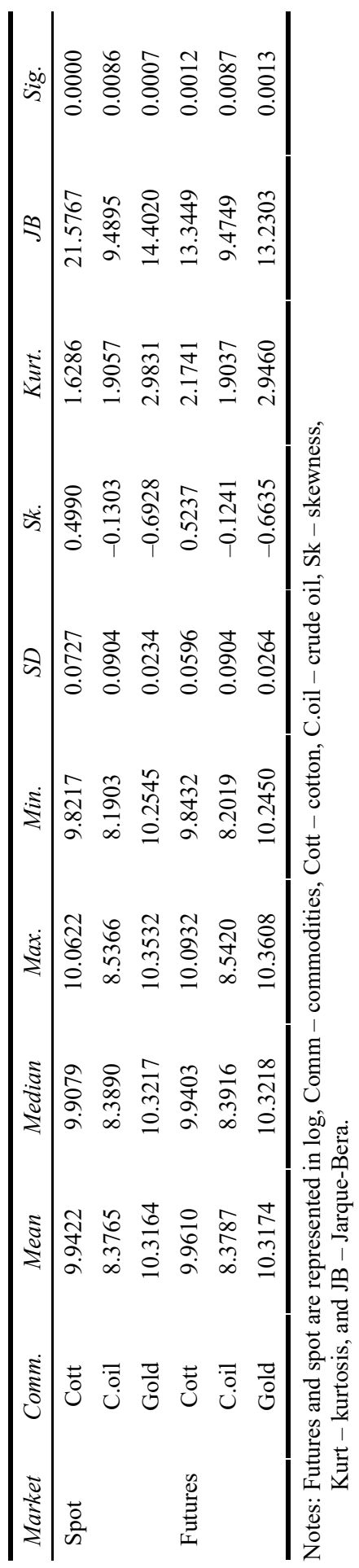


Table 2 Unit root test - commodities

\begin{tabular}{lcccc}
\hline Comm. & Variable & t-stats & M-test* & Sig. \\
\hline Cott & L(futures) & -0.8243 & -2.8776 & 0.8095 \\
& L(spot) & -0.4697 & -2.8777 & 0.8929 \\
& Interest rate & 3.8097 & -2.8775 & 1.0000 \\
C.oil & L(futures) & -0.8606 & -2.8775 & 0.7987 \\
& L(spot) & -0.6893 & -2.8775 & 0.8455 \\
& Interest rate & 3.8097 & -2.8775 & 1.0000 \\
Gold & L(futures) & -0.5524 & -2.8775 & 0.8766 \\
& L(spot) & -0.5833 & -2.8775 & 0.8700 \\
& Interest rate & 3.8097 & -2.8775 & 1.0000 \\
\hline
\end{tabular}

Notes: $\mathrm{H}_{0}$ : variables have unit roots, Comm - commodities, Cott - cotton,

C.oil - crude oil, and *modular test critical value at $5 \%$.

Table 3 Unit root test for differenced variables - commodities

\begin{tabular}{lcccc}
\hline Comm. & Variable & t-stats & M-test & Sig. \\
\hline Cott & L(futures) & -14.6256 & -2.8777 & 0.0000 \\
& L(spot) & -10.5438 & -2.8777 & 0.0000 \\
& Interest rate & -19.5451 & -2.8777 & 0.0000 \\
\multirow{4}{*}{ C.oil } & L(futures) & -13.6680 & -2.8776 & 0.0000 \\
& L(spot) & -12.9877 & -2.8776 & 0.0000 \\
& Interest rate & -19.5451 & -2.8777 & 0.0000 \\
\multirow{3}{*}{ Gold } & L(futures) & -13.4930 & -2.8777 & 0.0000 \\
& L(spot) & -14.2291 & -2.8777 & 0.0000 \\
& Interest rate & -19.5451 & -2.8777 & 0.0000 \\
\hline
\end{tabular}

Note: $\mathrm{H}_{0}$ : differenced variables have unit roots, Comm - commodities, Cott - cotton,

C.oil - crude oil, and *modular test critical value at $5 \%$.

As it is evident, we are conveniently able to reject the null hypothesis postulating the presence of unit roots and conclude that the transformed first-differenced variables exhibit stationarity, i.e., $I(0)$. We now proceed with the Johansen (1991) cointegration test, with the underlying null hypothesis that there are none or zero cointegrating vectors. The Johansen cointegration test procedure involves examining the null hypothesis surrounding no cointegration between the variables. In essence, the rejection of the null hypothesis implies that the variables are cointegrated. In keeping with the cost-of-carry model employed in the paper, it is useful to apply the Johansen-test procedure as the underlying theoretical model postulates the cointegrating relationship between the futures and spot prices. The results underlying the indices of the three commodities - cotton, crude oil and gold - are delineated in Table 4. Clearly, the results indicate that we can reject the null hypothesis, which asserts no cointegration at $1 \%$ level of significance. From the observed $p$-values, we find evidence that in all the three commodities led by cotton, crude oil and gold, there are at most two cointegrating vectors. 
Table 4 Johansen cointegration test - commodities

\begin{tabular}{lcccc}
\hline Comm. & Vectors & MT-stats & M-test & Sig. \\
\hline Cott & 0 & 33.1870 & 29.7971 & 0.0196 \\
& At most 1 & 2.9477 & 15.4947 & 0.9692 \\
& At most 2 & $1.69 \mathrm{E}-05$ & 3.8415 & 0.9990 \\
C.oil & 0 & 370.7199 & 29.7971 & 0.0001 \\
& At most 1 & 6.5763 & 15.4947 & 0.6274 \\
& At most 2 & 0.0056 & 3.8415 & 0.9394 \\
Gold & 0 & 136.9601 & 29.7971 & 0.0001 \\
& At most 1 & 2.9620 & 15.4947 & 0.9686 \\
& At most 2 & 0.0097 & 3.8415 & 0.9212 \\
\hline
\end{tabular}

Notes: Comm - commodities, Cott - cotton, C.oil - crude oil, Vectors - hypothesised number of cointegrating vectors, MT-stats - modular trace statistics, and

*modular test critical value at $5 \%$.

Having established that in all the indices the series represented by futures, spot, and interest rate are cointegrated, we present the cointegration regression statistics depicting the coefficient values of the variables, along with their respective $p$-values, in Table 5.

Table 5 Cointegration regression stats - commodities

\begin{tabular}{lcccc}
\hline Comm. & Variable & Coeff. & MT-stats & Sig. \\
\hline Cott & L(spot) & 0.6682 & 8.2908 & 0.0000 \\
& Rate & 0.0101 & 1.6210 & 0.1068 \\
C.oil & L(spot) & 0.9964 & 63.9589 & 0.0000 \\
& Rate & 0.0006 & 0.4028 & 0.6876 \\
\multirow{3}{*}{ Gold } & L(spot) & 1.1018 & 55.5572 & 0.0000 \\
& Rate & 0.0022 & 4.3637 & 0.0000 \\
\hline
\end{tabular}

Notes: Dependent variable: L(futures), independent variable: L(spot),

Comm - commodities, Cott - cotton, C.oil - crude oil, Rate - interest rate,

Coeff. - coefficient, MT-stats - modular trace statistics.

The cointegration regression equation may be expressed as follows:

$$
f=\alpha+b_{1} \times s+b_{2} \times r
$$

where

$$
\begin{array}{ll}
f & \mathrm{~L} \text { (futures) } \\
s & \mathrm{~L} \text { (spot) } \\
r & \text { rate. }
\end{array}
$$

From the cointegration results, it may be observed that across all the three commodities, the coefficient values of $\mathrm{L}$ (spot) are almost close to unity and statistically significant at $1 \%$. The coefficient values of rate are observed to be statistically insignificant with the exception of gold. 
In order to test the single and joint hypotheses surrounding the cost-of-carry model, we perform the Wald-statistic (asymptomatically distributed as $\chi^{2}$ ) of coefficient restrictions. It is computed as shown below:

$$
\text { Wald statistic }(W)=\left[\frac{(n-k)(R R S S-U R S S)}{U R S S}\right] \approx \chi^{2}
$$

where

$n \quad$ number of observations

$k \quad$ number of regressors in the unrestricted regression

RRSS restricted residual sum of squares

URSS unrestricted residual sum of squares.

It is useful to note that in scenarios where a regression function involves finite samples with the testable hypotheses being linear (as in $\mathrm{H}_{0}: \beta_{1}=1$ ), the F-statistic and chi-square yield exactly similar values. ${ }^{2}$ By imposing a coefficient constraint in an unrestricted regression, we seek to observe if the residual sum of squares would increase considerably. If indeed this is the case, it would be concluded that the restrictions were not supported by the data, leading to a rejection of the null hypothesis (Brooks, 2014). The $\mathrm{W}$ results are depicted in Table 6.

Table 6 Wald test for coefficient restriction - commodities

\begin{tabular}{lccc}
\hline Comm. & Restrictions & Chi-square value & Sig. \\
\hline Cott & $\mathrm{C}(\alpha)=1$ & 16.9542 & 0.0000 \\
& $\mathrm{C}(\beta)=1$ & $25,080.75$ & 0.0000 \\
& $\mathrm{C}(\alpha)=1, \mathrm{C}(\beta)=1$ & $157,995.3$ & 0.0000 \\
C.oil & $\mathrm{C}(\alpha)=1$ & 0.05424 & 0.8158 \\
& $\mathrm{C}(\beta)=1$ & $443,250.7$ & 0.0000 \\
& $\mathrm{C}(\alpha)=1, \mathrm{C}(\beta)=1$ & $2,098,812$ & 0.0000 \\
Gold & $\mathrm{C}(\alpha)=1$ & 26.3594 & 0.0000 \\
& $\mathrm{C}(\beta)=1$ & $4,009,716$ & 0.0000 \\
& $\mathrm{C}(\alpha)=1, \mathrm{C}(\beta)=1$ & $4,324,212$ & 0.0000 \\
\hline
\end{tabular}

Note: Comm - commodities, Cott - cotton and C.oil - crude oil.

From Table 6, we can observe that while in all the cases the null hypothesis surrounding $\alpha=1$ cannot be rejected, we are able to reject $\beta=1$ in all the cases at a significance level of $1 \%$. Accordingly, under the single hypothesis testing, we are able to reject the cost-of-carry model. The joint hypothesis underlying $\alpha=\beta=1$ is rejected in all the three cases at a significance level of $1 \%$. We, therefore, reject the cost-of-carry model for all three commodities led by cotton, crude oil and gold, which further fails to support the underlying theoretical postulate surrounding the market efficiency of commodity markets in India. 


\section{Discussion of results}

Our results are consistent with Joyeux and Milunovich (2010), who rejected the cost-of-carry model, indicating the absence of market efficiency in the carbon-futures market. Similar to Inani (2018), who also observed a price discovery process in the case of futures prices, but not in the case of the spot prices of commodities, we find no evidence to support the equilibrium surrounding the cost-of-carry model. In a frictionless market adhering to the principles of market efficiency, traders must not have scope to earn abnormal profits arising from arbitrage opportunities. However, discrepancies arising out of inefficiencies in the price discovery in the spot market imply that traders seize opportunities to exploit price-differentials in the spot and futures markets, resulting in profitable deals.

The problem is particularly more pronounced in EMs like India, as the spot prices of commodities are influenced by a complex mix of geo-politico-economic variables. Take the case of cotton as an example. Along with the natural factors determining the output of cotton and the resultant government policies in terms of assigning a minimum support price (MSP) for the produce, market prices are ultimately impacted by the prevalent demand-supply function. In the absence of efficient technology, the time-lag in factoring the previous variables implies that commodity spot prices do not necessarily corroborate their intrinsic value.

Even as commodity futures prices tend to be informationally efficient, the lack of real-time synchrony with spot prices implies that speculators and short-term traders are now at liberty to make profitable trades. As market-makers, speculators play an important role in maintaining liquidity in the futures market. In contravention to the underlying function of hedging supported by futures, when commodity traders in collaboration with speculators start dictating spot prices of commodities is when fears of large-scale rigging start surfacing. This is precisely what occurred in the case of the scandal surrounding NSEI when the promoters failed to deliver the physical commodities, leading to a steep rise in the spot prices of commodities. One of the main accusations directed against the promoters was their culpability in manipulating spot prices taking cue from futures prices.

\section{Summary and conclusions}

In the light of the recently imploded NSEI scandal, our paper makes an influential contribution to the literature by exploring the market efficiency surrounding the commodity markets in India to guide researchers and policymakers to devise efficient mechanisms and actions in dealing with the trading of commodities in the Indian financial markets. The investigation is carried out by empirically examining the cost-of-carry model. Both the single hypothesis and joint hypothesis testing rejected the cost-of-carry model, implying that in the absence of market efficiency, arbitrageurs should be in a position to exploit the price differentials existing across futures and spot prices in both commodity and equity markets so as to earn abnormal returns.

While arbitrageurs dealing in equities would be required to strictly operate within the rules established by the capital markets regulator (SEBI), the scope of scrutiny is by far restricted to a greater degree in commodities. In the wake of the recently unfolded scam in NSEI, commodity market regulators should be mindful to a greater degree about the 
scrutiny of trading practices and put robust control systems in place in order to prevent the occurrence of market excesses in the future. In the ongoing spate of trade wars and geopolitical tensions, an EM like India can ill-afford social skirmishes arising from spiralling commodity prices, which in turn may be driven by zealous traders determined to manipulate markets. Deriving potential lessons from the Indian experience, policymakers and regulators of the emerging and under-developed markets will be well served to streamline the regulation of futures markets in commodities and prevent unscrupulous traders from manipulating the markets and jeopardising the interests of the common investors. An effective regulation of futures markets would play an important role in safeguarding the functioning of spot markets, as well. In keeping up with the experience of Indian regulators who have proposed the idea of compulsory physical delivery for selected commodities, it potentially offers a practical idea worthy of emulation to curb speculative activities directed at distorting the equilibrium of spot prices of commodities.

In this study, our inferences have been derived based on a shorter sample horizon. An interesting extension would be to observe the feasibility of market efficiency over a longer time period. Furthermore, future studies could be devoted to employing the cost-of-carry model to investigate cases similar to the NSEI case in other EM economies, which would allow intercountry analyses.

\section{Acknowledgements}

The authors would like to thank the Editor and the anonymous reviewers for their valuable feedback on the previous version of this manuscript.

\section{References}

Beck, S.E. (1994) 'Cointegration and market efficiency in commodities futures market', Applied Economics, Vol. 26, No. 3, pp.249-257.

Brenner, R.J. and Kroner, K.F. (1995) 'Arbitrage, cointegration, and testing the unbiasedness hypothesis in financial markets', Journal of Financial and Quantitative Analysis, Vol. 30, No. 1, pp.23-42.

Brooks, C. (2014) 'A brief overview of classical linear regression model', in Brooks, C. (Ed.): Introductory Econometrics for Finance, pp.75-133, Cambridge University Press, Cambridge.

Chan, K., Chan, K.C. and Karolyi, G.A. (1991) 'Intraday volatility in the stock index and stock index futures markets', Review of Financial Studies, Vol. 4, No. 4, pp.657-684.

Charles, A., Darné, O. and Kim, J.H. (2015) 'Will precious metals shine? A market efficiency perspective', International Review of Financial Analysis, Vol. 41, pp.284-291.

Choudhry, T. and Osoble, B.N. (2015) 'Nonlinear interdependence between the US and emerging markets' industrial stock sectors', International Journal of Finance and Economics, Vol. 20, No. 1, pp.61-79.

Crowder, W.J. and Phengpis, C. (2005) 'Stability of the S\&P 500 futures market efficiency conditions', Applied Financial Economics, Vol. 15, No. 12, pp.855-866.

Davidson, R. and MacKinnon, J.G. (1993) Estimation and Inference in Econometrics, 1st ed., Oxford University Press, New York.

De Bondt, W.F.M.D. and Thaler, R. (1985) 'Does the stock market overreact?', Journal of Finance, Vol. 40, No. 3, pp.793-805. 
DNA India (2012) 'Lok Sabha clears banking bill after govt drops futures trading clause', DNA India, 18 December.

Dwyer, G.P. and Wallace, M.S. (1992) 'Cointegration and market efficiency', Journal of International Money and Finance, Vol. 11, No. 4, pp.318-327.

Frontline (2013) 'On the spot scam', Frontline, 20 September [online] https://frontline.thehindu. com/columns/C P Chandrasekhar/on-the-spot-scam/article5085281.ece.

Gujarati, D.N. and Porter, D.C. (2009) Time Series Econometrics: Some Basic Concepts, McGraw Hill, Singapore.

Hansen, L.P. and Hodrick, R.J. (1980) 'Forward exchange rates as optimal predictors of future spot rates: an econometric analysis', The Journal of Political Economy, Vol. 88, No. 5, pp.829-853.

Heaney, R. (2002) 'Does knowledge of the cost of carry model improve commodity futures pricing forecasting ability? A case study using London Metal Exchange lead contract', International Journal of Forecasting, Vol. 18, No. 1, pp.45-65.

Hemler, M.L. and Longstaff, F.A. (1991) 'General equilibrium stock index futures prices: theory and empirical evidence', Journal of Financial and Quantitative Analysis, Vol. 26, No. 3, pp.287-308.

Hull, J.C. (2015) Options, Futures, and Other Derivatives, 9th ed., Pearson Education, New Jersey.

Inani, S.K. (2018) 'Price discovery and efficiency of Indian agricultural commodity futures market: an empirical investigation', Journal of Quantitative Economics, Vol. 16, No. 1, pp.129-154.

Johansen, S.J. (1991) 'Estimation and hypothesis testing of cointegration vectors in Gaussian vector autoregressive models', Econometrica, Vol. 59, No. 6, pp.1551-1580.

Joyeux, R. and Milunovich, G. (2010) 'Testing market efficiency in the EU carbon futures market', Applied Financial Economics, Vol. 20, No. 10, pp.803-809.

Kellard, N., Newbold, P., Rayner, T., and Ennew, C. (1999) 'The relative efficiency of commodity futures market', Journal of Futures Markets, Vol. 19, No. 4, pp.413-432.

Malkiel, B.G. (2003) 'The efficient market hypothesis and its critics', Journal of Economic Perspectives, Vol. 17, No. 1, pp.59-82.

McKenzie, A.M. and Holt, M.T. (2002) 'Market efficiency in agricultural futures markets', Applied Economics, Vol. 34, No. 12, pp.1519-1532.

MCX India (2018) Physical Delivery Guide, MCX India, Mumbai.

Rittler, D. (2012) 'Price discovery and volatility spillovers in the European Union emissions trading scheme: a high frequency analysis', Journal of Banking \& Finance, Vol. 36, No. 3, pp.774-785.

The Wall Street Journal (2019) 'Russia, Saudi Arabia reach oil output agreement ahead of OPEC talks', The Wall Street Journal, sl.

Wahab, M. and Lashgari, M. (1993) 'Price dynamics and error correction in stock index and stock index futures market: a cointegration approach', Journal of Futures Markets, Vol. 13, No. 7, pp.711-742.

Zavadska, M., Morales, L. and Coughlan, J. (2018) 'The lead-lag relationship between oil futures and sport prices - a literature review', International Journal of Financial Studies, Vol. 6, No. 4 , pp.1-22.

\section{Notes}

1 For an excellent theoretical discussion on cost-of-carry, see Hull (2015).

2 For linear regression models, with or without normal errors, there is of course no need to look at LM, W and LR at all, since no information is gained from doing so over and above what is already contained in F (Davidson and MacKinnon, 1993). 


\section{Appendix 1}

\section{Volume and value of commodity contracts traded}

Figure A1 Movement of commodity futures: number of traded contracts and value of traded contracts in lakhs of INR (see online version for colours)

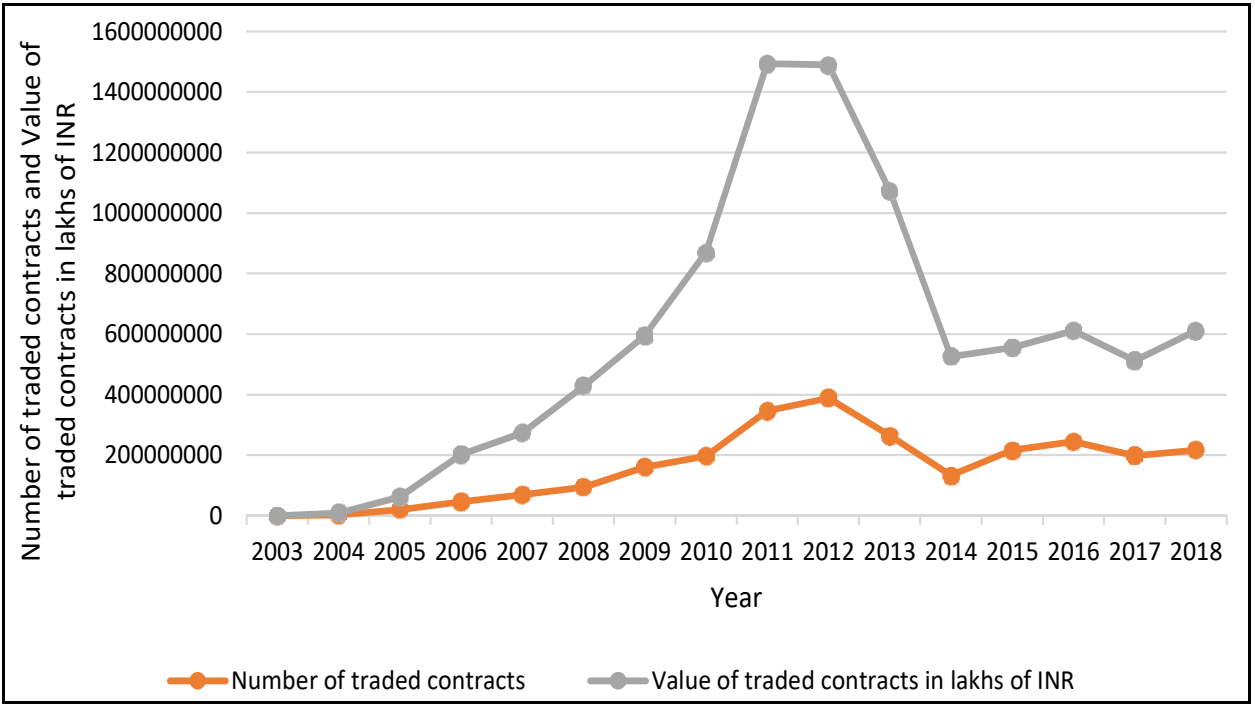

\section{Appendix 2}

Note on trading in commodity futures in India (MCX India, 2018)

The trading of commodity futures in India is undertaken by the Multi Commodity Exchange of India Limited (MCX India, http://www.mcxindia.com). Commodity futures contracts traded under MCX India are primarily regulated by the Securities Exchange Board of India (SEBI: http://www.sebi.gov.in). Commodity futures contracts were previously regulated by the Forwards Market Commission (FMC) regulator. However, as a result of the NSEI fiasco, FMC was merged with SEBI. Subsequently, SEBI has played an active role in curbing speculative practices aimed at eroding investors' confidence by promulgating effective regulations with regards to market operations related to commodity futures in India. In hindsight, it is useful to note that commodity futures in India are traded with the following four categories:

1 agriculture - black pepper, cardamom, castor seed, cotton, crude palm oil, mentha oil, RBD palmolein and rubber

2 base metal - aluminium, brass, copper, lead, nickel and zinc.

3 bullion - gold and silver

4 energy - crude oil and natural gas. 
Trading of commodity futures in India is settled primarily in the following two forms:

1 Cash settlement - Under this mechanism, there is no physical delivery of the commodity, with the parties settling the trade by exchanging profit, which is determined on the basis of the closing futures price on the expiry day vis-à-vis the agreed price. Presently, all products within base metal are compulsorily cash settled in India.

2 Physical settlement - Under this mechanism, the futures contract is settled on the day of the expiry through physical settlement of the commodity. In essence, this works as the pristine form of hedging as traders settle the physical commodity at the agreed price thereby eliminating the risks arising out of fluctuations in the market price. Presently, in India, all the agricultural commodity futures are traded under compulsory physical settlement.

In keeping with the lessons derived from the fallout of the NSEI scandal, SEBI has implemented bolder moves recently by experimenting compulsory physical delivery in respect of aluminium and zinc along with cash delivery. It is argued that with compulsory physical delivery there will be greater accountability on the part of the traders and work to curb speculative practices, which become more pronounced in the case of cash settlement. 